\title{
ANALYSIS OF HIGH-RISE APARTMENT ACCIDENT BASED ON FTA
}

\author{
Karthick.R ${ }^{1}$, Karthick.K.N ${ }^{2}$ \\ ${ }^{I}$ Student, Department of Industrial Safety Engineering, Knowledge institute of technology, Tamil Nadu, India \\ ${ }^{2}$ Assistant Professor, Department of Mechanical Engineering, Knowledge institute of technology, TamilNadu, India
}

\begin{abstract}
In recent years, the number of apartment building fires keeps on increasing which causes threat to human life and leads to huge damage on materials and resources. The paper aims at studying and analysis on apartment fire accidents and providing some recommendations and suggestions on real time application practise. In this paper a case study on accident causes due to fire is analysed in detail, the important events of incidents are being indicated. Moreover recommendation for fire safety equipment installation for high rise apartment and suggestion for safe egress on emergency is proposed.
\end{abstract}

Keywords: Accident causes analysis, Fire safety, High rise apartment, Fire safety Devices.

\section{INTRODUCTION}

In recent years most of the building fire accident is happened in residential buildings. In India residential apartment are developed in the way of multi-building and fully modernized apartments. On the other hand, modernized building is not suitable for fire safety designs. So it is difficult to cut off the fire in high rise building. The fire accident in large buildings is totally different from the fire accident in the high rise apartments. One of the main reasons for the quick spreading of the apartment fire is that the neighboring house is closely built. Accident cause analysis is a process of understanding and characterizing the fire hazard in high rise apartment for more protection and prevention of fire [3].To improve the fire safety of high rise apartment and to save the life of the residential people, the safety measures for the building should be taken at the design stage of the construction and also follow the National building code. In this paper a case study of an apartment fire is discussed and the reason for the accident was analyzed by fault tree analysis method. To find out the various causes for the fire accident in that apartment and some recommendations for the fire safety system and fire safety devices are also discussed in order to prevent the fire accident and save the life of the people.

\section{FAULT TREE ANALYSIS ON APARTMENT}

\section{FIRE ACCIDENT}

\subsection{Apartment Accident Overview}

November 2012, Hyderabad, India a huge fire accident where occur at the high rise apartment in the city center place. In the massive fire six people were killed which includes a new born baby too. A week-baby and two women were killed, three others were heavily injured. It was one of the worst fire accidents which Hyderabad city ever faced. Three fire tenders and the crew of firefighters battled for nearly two hours to make the situation under control. The fire started in a shed where plastic and other combustible materials were stored, which was used for film shooting.
Later the fire spread towards the residential building. It became impossible for the residents to escape because of the thick smoke in the staircase, which was close to the shed. Through the other side of the building the firefighting personnel and the locals rescued some people. Most important thing that people is not aware of apartment fire accident. The problem identify in the accident are based on building characteristics as their height of the building, population density, fire load in the residential. Fire spread it is difficult to put off the fire and very hard to evacuate [1].This accident is one of the worst fire accident in the city people was faced.

\subsection{Fault Tree Analysis Preparation}

Fault tree analysis will not only analyzed the direct cause of the accident but also find the basic cause of the accident through stepwise analysis method finally shows the main cause of the accident. It shows the direct and indirect causes of the accident. In this case study accident analyzes the possible reason for the spread of fire is the accumulated plastic in the nearby temporary shed. Based on these, fire hazard factors on the high rise apartment are analyzed using the fault tree analysis method[2].A fig 1 show is fault tree analysis diagram for apartment fire method finally shows the fire development cause of the accident. Table 1 clearly shows the sign meaning in the fault tree analysis. 


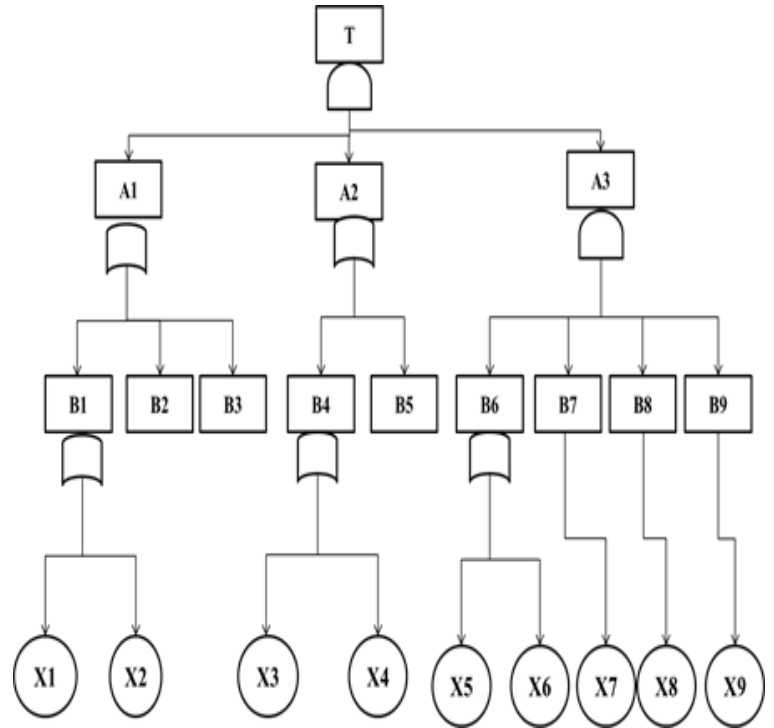

Fig.1 Fault tree analysis diagram of the apartment fire accident.

Table 1 Meaning of each sign

\begin{tabular}{|l|l|}
\hline SIGN & MEANING \\
\hline T & Residential apartment fire \\
\hline A1 & Fire source \\
\hline B1 & Electrical fire \\
\hline B2 & Cooking fire \\
\hline B3 & Fumes welding \\
\hline X1 & Short circuit \\
\hline X2 & Wire damage \\
\hline A3 & Fire prevention and protection technique \\
\hline B6 & Fire alarm \\
\hline B7 & Fire extinguisher \\
\hline B8 & Smoke detector \\
\hline B9 & Fire sprinkler \\
\hline X5 & Alarm delay \\
\hline X6 & Failure of alarm \\
\hline X7 & No fire extinguisher \\
\hline X8 & Not detect properly \\
\hline X9 & Improper maintenance \\
\hline A2 & Fuel source for fire \\
\hline B4 & Flammable liquid \\
\hline B5 & Plastics \\
\hline X3 & Petrol \\
\hline X4 & Gasoline \\
\hline & \\
\hline
\end{tabular}

By the fault tree analysis, fire development causes can be analyzedand summarized some sources when the high rise apartment fire accident happens, the firefighting and egress plays an important role, but it is difficult to avoid the fire completely. By avoid accident use the techniques like the fire prevention, protection and safety devices like fire alarm, fire extinguisher, smoke detector, fire sprinkler etc. [2].A Fig 2 shows that fault tree analysis of fire development in the apartment fire.

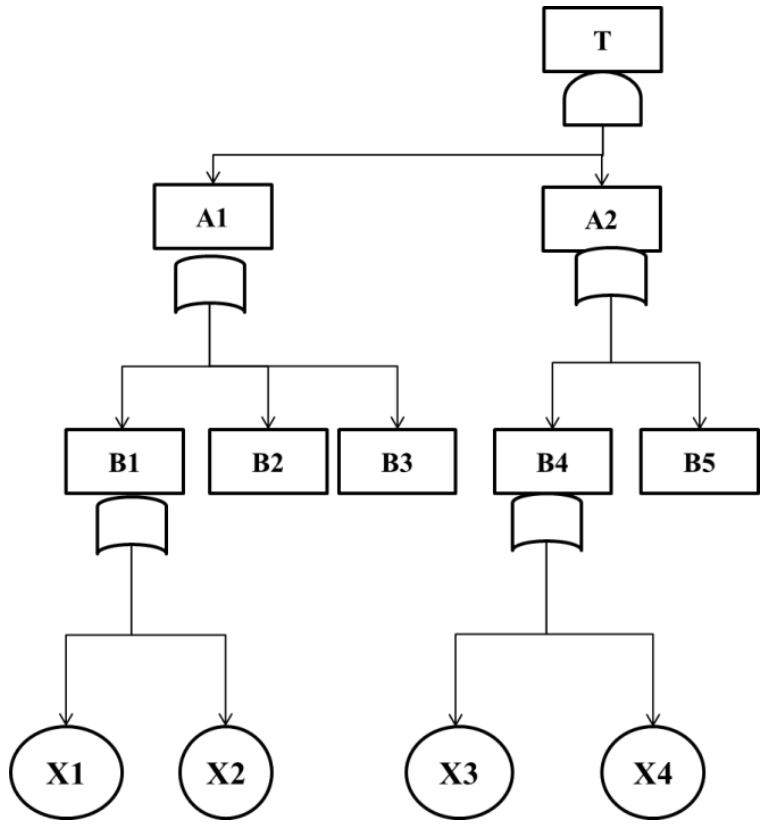

Fig.2 Fault tree analysis diagram of fire development.

\subsection{Identification of Risk Source in the Apartment} Fire

According to the classification fire building accident the main causes of fire were discussed and analyzed

(1). Electrical fire is the most dangerous fire in the high rise apartment buildings it is the top most repeated to causes fire accident in the past scenario. Short circuit and wire damage are the two major reason of the accident. Where an electrical appliance used in the residential are poor conducting devices like (hair dryers, portable heater, cooking appliances).check that all the wires and cables were protected by fuses. Useproper current rating forthe air condition it will minimize their fire accident.

(2). Cooking fire is second leading cause of fire in apartment. Never leave cooking while unfulfilled. A good housekeeping prevents the half of the fire accident in the kitchen. Most cooking fire involve in the stovetop. Never store flammable liquids in the kitchen Keep match box and lighters in the locked cabinet.

(3). Fumes welding is the another cause of accident nearby buildings location some jointing and cutting works where held at the time. The most dangerous hazard sparks emission to get easily fire on the source material.

(4). Flammable items like gasoline, benzene, naphtha, or similar flammable liquids are never store inside of the buildings. Flammable things are quickly catch the fire by heat radiation storage of plastics get easily by slight change of hot temperature. In this accident plastic plays the major role for causes the storage of plastics must place in the nonhazardous area.

(5). Smoke detector is the initial the fire indicating equipment. According to the IS 2189:1976 it is suggested that rapid growth of industries and buildings place the fire 
safety devices. If it is present $50 \%$ of fire will protected. Smoke detector is placed the spacing between the detector shall not exceed $12 \mathrm{~m}$ in the ordinary area, $18 \mathrm{~m}$ in the corridors[5].It also play and preventive action takes place before the fire occur it should not install near by the window, corridors and doors.

(6). Fire alarm system according to Indian standard IS2189:1976 it is suggested to place the devices more hazardous area initiating devices such as manual fire alarm box, automatic detection. The combination of the system gives an audible and visible thing. It protects the whole occupant at the initial stage of the fire.

(7). Fire sprinkler is utilizing water from direct application onto the fire and heat. Which cause reduces the temperature and get cooling of combustion process and prevent from the fire. This system detect, isolate, attack and control of fire. Sprinklers are designed to reduce the temperature rating depends upon the risk[5].Sprinkler system plays an outstanding record in fire statistics around the world successfully suppressed $99 \%$ of fire protection. Almost $50 \%$ of the fire will controlled by this system

\section{PREVENTIVE STRATEGIES ON THE HIGH RISE APARTMENT}

Through the above analysis, the reason of a fire accident can be divided into two the modern safety technology and management performance related to safety; if these two systems can be done well the probability of building fire accident will be reduced and improve more safety awareness to people. The following will gives the brief analyze of the two systems.

(1). Modern safety technology Indian standard code suggests that improve fire safety aspect at the residential building. According to that, Fire protected doors were used inside the building as per the standard Fire resistant walls designed to stop a fire spreading these are similar to the water-proof. Fire proof paint will suggest to coat in the wall and roofs. Easily flammable material was avoided in the floor. We can also solve fire by some technical level of the Fire sprinkler system, auto alarm system, smoke detector, automatic fire alarm detection, smoke alarm, heat detection, and it is hoped that fire can be prevented and controlled from the technical aspects[2].In addition, local governments and fire departments should be updated to improve the firefighting equipment and conduct fire drill to the people.

(2). Management performance related to safety National building code suggests that improve fire safety aspect at the residential building. Management must concentrate the design of construction. Mock drill where conduct once in a year to identifying the two ways of exit from every room and to have better knowledge on escape planning. Know the plan of safe egress, all window door should open easily .Visible commitment provide from the top level management. Emergency onsite plan must provide every apartment building. Periodic awareness program where conduct. Top level management must understand the important of safety and express to all people.[2].Increase the safety culture and improve the level of safety increase in the apartment building. At last more necessary to install\& maintains of safety devices.

\section{RECOMMENDATIONS}

At, the time of fire or emergency period keep you analyzed that building is whether fire-proof building or non-fire proof building. If your building is fire proof stay inside the building try to solve the fire sources[4].It is non-proof building occupant immediately leave the building, analyses the time management to evacuate at safe area between the sounds of alarm and to reach safe assembly point. In according to the nationally recognized building code every building should have an emergency egress system. These code will contain minimum standard for the emergency exit system i.e. the pathway that provide evacuation routes from every part of the building to the outdoor at ground level[5].Fire drill is important for all homes included apartment building you need to know the basics of escape planning.

\section{CONCLUSIONS}

The study revels on the high rise apartment fire, which is one among the major accident. A case study on high rise apartment was taken and analyzed deeply by accident cause analysis in the high rise apartment fire accident. The accident cause analysis explains the cause of fire and the basic events. It shows that negligence on planning, implementation and maintaining of safety management system is the major cause of accidents. By implementing the above recommendation the level of safety can be increased in high rise apartment; which helps in preventing fire accident. In order to guiding the high rise apartment fire prevention safety problem, this study remedial and countermeasure to provides some practical application of apartment building. This study can be taken as a ground work on safety issues in high rise apartment.

\section{ACKNOWLEDGEMENTS}

Mr.M.Karthikeyan, Assistant professor, University of petroleum and energy studies, Dhradun.

\section{REFERENCES}

[1]. LIU Xiuyu, ZHANG Hao*, ZHU Qingming (2012)."Factor analysis of high rise building fires reasons and fire protection measures",Procedia Engineering 45,643 -648 .

[2]. Chen Haitao ${ }^{\mathrm{a}, \mathrm{b}, *}$, Lou Leilei ${ }^{\mathrm{c}}$, QiuJiuzi ${ }^{\mathrm{d}}$ (2012)."Accident cause analysis and Evacuation countermeasures on the high-rise building fires", Procedia Engineering 43,23 - 27.

[3]. MA Qian-lia,b, HUANG Ting-lina,* (2011).“Analysis of and study on the difficulties in the fire protection design of large commercial complex", Procedia Engineering 11,302-307.

[4]. GuyleneProulx.(1995), "Evacuation time and movement in apartment buildings", Fire Safety Journal 24,229-246. 
[5]. V.K.Jain.,(2010)“Fire safety inbuilding”,second edition 2010,New age international publishers.

\section{BIOGRAPHIES}

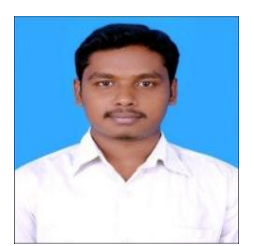

Mr. R. Karthick was born in Salem city, Tamil nadu, India in 1991. He received the B.E. degree in Electrical and Electronic Engineering from K.S.Rangasamy college of Technology, Tiruchengode, Tamil Nadu, India, in 2012. He is currently pursuing the M.E. degree in Industrial Safety Engineering at Knowledge Institute of Technology, Salem, Tamil Nadu, India.

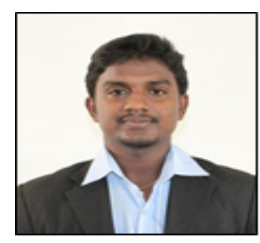

Mr. K. N. Karthick received the B.E. degree in mechanical engineering from K. S. Rangasamy College of Technology, Namakkal, Tamil Nadu, India, in 2010 and M.E. degree in Manufacturing Systems and Management from College of Engineering, Guindy, Anna University, Chennai, Tamil Nadu, India, in 2013. Since 2013, he has been an assistant professor with the Department of Mechanical Engineering at Knowledge Institute of Technology, Salem, Tamil Nadu, India 